\title{
Ibn Rušd vu par une source historique arabe : Ibn Abī Ușaybi‘a
}

\section{Hinda Al-Maliki}

\section{(2) OpenEdition \\ 12 Journals}

Édition électronique

URL : http://journals.openedition.org/beo/134

DOI : $10.4000 /$ beo.134

ISBN : 978-2-35159-260-8

ISSN : 2077-4079

\section{Éditeur}

Presses de l'Institut français du Proche-Orient

Édition imprimée

Date de publication : 1 janvier 2008

Pagination : 169-184

ISBN : 978-2-35159-038-4

ISSN : 0253-1623

\section{Référence électronique}

Hinda Al-Maliki, « Ibn Rušd vu par une source historique arabe : Ibn Abī Ușaybi'a », Bulletin d'études orientales [En ligne], Tome LVII | Janvier 2008, mis en ligne le 13 novembre 2009, consulté le 19 avril 2019. URL : http://journals.openedition.org/beo/134; DOI : 10.4000/beo.134 


\title{
IBN RUŠD VU PAR UNE SOURCE HISTORIQUE ARABE : IBN ABĪ UȘAYBI'A
}

\author{
Hinda AL-MALIKI \\ Université Lyon 3
}

\section{INTRODUCTION}

Ibn Rušd, Averroès en latin, né à Cordoue en 520/1126, décédé en 595/1198, un des plus célèbres commentateurs et philosophes arabes exerça une considérable influence sur le développement de la pensée occidentale du Moyen Âge. Néanmoins, on possède très peu d'informations sur sa propre vie. Même si on tente de dépouiller ses ouvrages, aucun renseignement important n'est fourni. Les quelques biographes arabes de son siècle et des siècles successifs lui ont consacré un nombre de pages très variable allant du simple paragraphe à deux ou trois pages au plus.

Étant donné que toute étude sur Ibn Rušd utilise obligatoirement ces sources, si minimes soient-elles, il nous a paru logique d'effectuer une étude et une analyse approfondie de ces textes historiques, lesquels ont servi tous les historiens contemporains de Renan ${ }^{1}$ à Fahrī ${ }^{2}$ en passant par Badawī. Certains, tels que Renan et Munk ${ }^{3}$, les ont plus exploités que d'autres.

Avant d'aborder l'étude d'une des sources, objet de cet article, je souhaite présenter l'ensemble des sources biographiques arabes qui ont traité Ibn Rušd suivant un ordre chronologique, c'est-à-dire du plus proche de l'époque d'Averroès au plus éloigné, ayant

1. E. RENAN : 1823-1892, écrivain, historien des religions et philosophe français. On considère que son œuvre résume à elle seule, par ses défauts comme par ses qualités, le XIX ${ }^{\mathrm{e}}$ siècle français. En 1852, dans sa thèse intitulée Averroès et l'averrö̈sme, il montre les dangers de l'orthodoxie qui arrêta chez les musulmans l'évolution de la pensée scientifique et philosophique. Cependant, il faut garder à l'esprit que l'œuvre de Renan a vieilli.

2. Māğid FAHRĪ, professeur libanais spécialiste de la pensée médiévale. Il est notamment l'auteur, en anglais, du classique A History of Islamic Philosophy, traduit dans plusieurs langues, et d'un ouvrage en arabe sur Ibn Rušd, Ibn Rušd, faylasūf Qurțuba («Ibn Rušd, le philosophe de Cordoue »), 1960. Cf. Averroès, Discours décisif, traduction inédite de Marc Geoffroy, introduction d'Alain de Libera, « Le discours décisif vu par les auteurs arabes modernes », p. 230 .

3. S. MunK : 1803-1867, orientaliste français d'origine allemande. Son intérêt principal porte sur l'histoire de la pensée juive. Il est connu pour sa traduction du Guide des égarés de Maïmonide (1856-1866). Dans Mélanges de philosophie juive et arabe (1859), il rassemble des études diverses accompagnées de textes originaux tous relatifs à la pensée médiévale juive et arabe. 
admis que le premier biographe est quasiment de l'époque d'Ibn Rušd et que le dernier lui est postérieur d'à peine deux siècles.

— Kitāb al-mu 'ğib fi talhìs ahbār ahl al-Mag̀rib de 'Abd al-Waḥīd al-Marrākušs̄i qui a été, selon L'Encyclopédie de l'Islam, vraisemblablement composé en 621/1224.

— Kitāb al-takmila li kitāb al-ṣila d'Ibn al-Abbār ${ }^{5}$, rédigé en 631/1233 et revu durant une vingtaine d'années.

\section{— 'Uyūn al-anbāa' fi țabaqāt al-ațibbāa' d'Ibn Abī Ușaybi ${ }^{6}{ }^{6}$ rédigé entre 640 et 667/}

1242 et 1268. Le Dictionnaire al-A 'lām donne l'année 643 de l'hégire.

- Al-Sifr al-awwal min kitāb al-ḍayl wa al-takmila li kitābay al-mawșūl wa al-șila de Abū 'Abd Allāh Muhammad al-Anșārī 7 .

- Tärīh al-islām d'al-Dahabīi ${ }^{8}$.

Nous ignorons pour ces deux derniers la date de leur composition.

Nous avons choisi de traiter ici l'un d'entre eux, Ibn Abì Ușaybi 'a, pour l'importance que son texte revêt du point de vue des divers éléments fournis sur la vie et l'œuvre d'Ibn Rušd. C'est aussi le seul auteur-source qui rapporte une liste considérable de titres d'ouvrages rédigés par Ibn Rušd. Il est également très intéressant de l'étudier pour effectuer une comparaison entre les différents auteurs-sources précités. Le nombre de maîtres qu'il cite dans la formation du jeune Ibn Rušd, l'énumération de noms de savants qui ont connu la disgrâce en même temps qu'Ibn Rušd et l'extrait du Kulliyât « Colliget » cité dans la biographie, sont autant d'éléments qui font d'Ibn Abī Ușaybi‘a un auteur biographique d'une grande

4. Né à Marrakech, d'où son nom al-Marrākušī, en 581/1185 et mort en 647/1250. Historien, auteur du livre intitulé al-Mu 'ğib fi talhịs ahbār ahl al-maġrib, édité par Dozy sous le titre The History of the Almohads. Cet ouvrage est intéressant du point de vue de l'histoire de l'Occident musulman, en particulier celle des Almohades ; d'autant plus qu'al-Marrākušì fréquenta la cour almohade et plusieurs hommes célèbres, notamment Abū Bakr Ibn Zuhr (Avenzoar) et le fils du philosophe Ibn Țufayl.

5. Connu pour être à la fois historien, traditionniste, littérateur et poète, Ibn al-Abbār est né à Valence en 595/ 1199 et fut mis à mort en 658/1260 en Tunisie. Il remplit les fonctions de secrétaire auprès des gouverneurs mu'minides de Valence. Il fut également cadi de Dénia. Son ouvrage est une suite à la Sila d’Ibn Baškuwāl.

6. Son nom complet est Ibn Abī Ușaybi‘a Muwaffaq al-Dīn Abū al-'Abbās Aḥmad ibn al-Qāsim ibn Khalīa ibn Yūnus al-Hazrağì. Connu pour être médecin et biographe issu d'une famille de médecins, il naquit à Damas après 590/ 1194 et il mourut en 668/1270. Il étudia sous des maîtres renommés. Il pratiqua la médecine dans les hôpitaux de Damas et du Caire pour se trouver ensuite au service de l'amīr 'Izz al-Dīn Aybak al-Mu'azẓami à Sarhad. Ibn Abī Ușaybi ‘a est connu

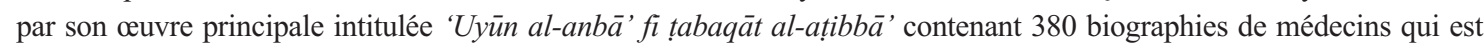
selon J. Vernet « d'une valeur inappréciable pour l'histoire de la science arabe ». Les biographies sont présentées par pays et génération (țabaqāt). L'ouvrage fut rédigé en deux volumes.

7. Né à Marrakech en 634/1237 et mort à Tlemcen en 703/1303. Historien, littérateur et cadi en chef à Marrakech sous les Mérinides. Sa fonction de juge va lui permettre, comme on le verra, d'étudier le procès d'Ibn Rušd sous un angle plutôt juridique, sans oublier que le fait d'être un juge en chef, tout comme Ibn Rušd, va davantage le rapprocher de ce dernier. Considéré comme dictionnaire biographique, le Dayl demeure un outil essentiel pour la connaissance des hommes célèbres de l'Occident musulman.

8. Né à Damas en 673/1274 et mort dans la même ville entre 748/1348 et 753/1352-3, il est considéré comme historien et théologien. Ses écrits sont nombreux. On remarque aussi qu'il fut également compilateur; ses ouvrages se distinguent par une composition soignée et de constantes références à ses autorités selon L'Encyclopédie de l'Islam. 
valeur pour l'étude d'Ibn Rušd. Les renseignements qu'il donne sont d'une rigueur historique qui nous permet, à l'aide de la compilation d'autres textes arabes sources, d'assembler le puzzle qui constituera une image cohérente d'Ibn Rušd.

Ibn Abī Ușaybi'a est largement connu des historiens de la médecine arabe médiévale car il constitue l'une des références majeures. Son ouvrage colossal 'Uyūn al-anbā' fi țabaqāt al-ațibb $\bar{a}^{\prime}$, comptant des centaines de biographies de médecins, n'était pas destiné à être l'une des sources historiques dans l'étude d'Ibn Rušd; en effet, rien ne laisse présager que cet auteur pourrait avoir un lien avec l'étude d'un philosophe cordouan du XII siècle si ce n'est peut-être un élément commun au deux hommes : leur intérêt pour la médecine.

Dans la préface de l'ouvrage, Ibn Abī Ușaybi'a donne les raisons qui l'ont poussé à rédiger ce livre. Ensuite, il expose ses desseins. Les objectifs de l'auteur ont donc été repris ici sous forme d'énumérations pour en synthétiser le principe.

1) « J'ai jugé bon de citer dans ce livre des dictons et des vues $[\ldots]$;

2) la détermination de leurs générations à travers leurs époques et leurs périodes $[\ldots]$;

3) j’y ai placé aussi un peu leurs propos, leurs histoires, leurs anecdotes et leurs débats [...] ;

4) citer quelques titres de leurs livres ${ }^{9}$;

5) j'ai inséré dans ce livre aussi un groupe d'hommes sages et de philosophes qui s'occupent de la science médicale et la connaissent [...];

6) des sommes de leurs conditions et anecdotes ainsi que les titres de leurs livres ${ }^{10}$;

7) et j'ai cité chacun d'eux à la place qui lui sied selon sa génération et son rang ${ }^{11}$. »

Ces derniers points précisés par l'auteur seront déterminants lorsque le texte source d'Ibn Abī Ușaybi'a concernant Ibn Rušd sera analysé. Au moment d'aborder ce texte, il faudra avoir à l'esprit au préalable le fait qu'il ne s'agit là que d'un sommaire plus ou moins long en fonction de l'importance de la biographie du personnage qui nous intéresse. Ceci peut être facilement vérifié si on compare les biographies du groupe médecins philosophes et les biographies des médecins à part entière. La conclusion tombe d'elle même : le deuxième groupe est nettement favorisé chez Ibn Abī Ușaybi'a et prend une ampleur considérable.

\section{ÉLÉMENTS INTÉRESSANTS DANS SON TEXTE}

Pour ce qui a trait à Ibn Rušd nous allons examiner ce que peut nous apprendre de plus la rubrique consacrée à notre penseur. Tout d'abord, les éléments que fournit Ibn Abī Ușaybi ‘a sur la formation et les maîtres d'Ibn Rušd sont un peu éparpillés sur l'ensemble du texte, mais sont de première importance.

9. Ici, l'auteur indique bien que les listes des livres qu'il va énumérer pour chaque biographie ne seront pas exhaustives.

10. Là, l'auteur semble avertir le lecteur que, pour cette catégorie de gens (médecins-philosophes), il en sera seulement question sommairement, de même que pour la liste de leurs ouvrages. C'est une remarque qu'il faut prendre en compte pour la biographie d'Ibn Rušd car il appartient à cette catégorie.

11. Cf. Iвn Aві̄ UșAYBi'A, 'Uyūn al-anbā' fi țabaqāt al-ațibbāa', édition Dār Maktabat al-Hayāt, Beyrouth, revue et corrigée par le docteur Nizār Riḍā, p. 7-8. 
Comme c'est le côté médical qui intéresse principalement Ibn Abī Ușaybi'a, il va l'aborder juste après. Il est le seul auteur qui cite intégralement tout un texte du Kitāa alkulliyāt en médecine ; ce qui veut dire que tout en accomplissant sa mission de biographe, il a consulté les livres d'Ibn Rušd ; cela traduit un esprit rigoureux et, par conséquent, donne plus de poids au contenu de son ouvrage ${ }^{12}$.

Il y a également un autre élément important dans cette citation que E. Renan n'a pas manqué de relever : il semblerait que grâce à cette citation, nous possédions l'original d'une petite partie d'un texte d'Ibn Rušd qui est aujourd'hui perdue et dont ne subsistent que les traductions hébraïque et latine, ce qui permet donc de faire la comparaison entre l'original et les traductions.

Ensuite, Ibn Abī Ușaybi ‘a nous parle du lien d'Ibn Rušd avec le pouvoir et ensuite de sa disgrâce. Notons aussi qu'il est le seul auteur qui parle d'un groupe de gens frappés par la disgrâce à l'instar d'Ibn Rušd ${ }^{13}$ tandis que dans le texte d'Ibn al-Abbār, Ibn Rušd semble être le seul à subir cette disgrâce. Pour al-Anșārī, en revanche, son emploi du duel présume qu'ils étaient deux à subir la disgrâce. Quant à al-Dahabī, il ne fait que citer Ibn al-Abbār et Ibn Abī Ușaybi ‘a. En fait, celui qui a le plus parlé de la disgrâce d'Ibn Rušd c'est al-Anșārī et celui qui en a le moins parlé c'est Ibn al-Abbār bien qu'il avoue que son épreuve était célèbre.

\section{COMPARAISON AVEC LES AUTRES TEXTES SOURCES}

En premier lieu, on notera que le nom d'Ibn Rušd n'est pas donné au complet comme chez Ibn al-Abbār.

En second lieu, les qualités personnelles d'Ibn Rušd sont décrites de manière différente d'un biographe à un autre. Ibn al-Abbār avec son style direct donne l'impression de le connaître ; Ibn Abī Ușaybi 'a procède par l'intermédiaire de quelqu'un d'autre quand il rapporte les propos du cadi Abū Marwān al-Bāğìi ; de plus, il n'insiste pas trop sur ses qualités personnelles à l'instar du premier, puisque nous relevons seulement, au début du texte, l'expression « renommé pour son grand mérite » (mašhūr bi al-fadll).

Avec al-Marrākušì, il partage l'anecdote sur l'appellation donnée au calife lors de la description de la girafe. Par contre, il n'est pas d'accord avec al-Marrākušĩ sur la date de la mort d'Ibn Rušd. Ce semblant de différence peut être le résultat d'une interprétation faite par Ibn Abī Ușaybi'a puisque al-Marrākušì écrit : « [...] il y mourut à la fin de l'année 594 [...] ${ }^{14}$ », alors que chez Ibn Abī Ușaybi‘a « [...] la mort du cadi Abū al-Walīd Ibn Rušd, que Dieu lui soit miséricordieux, eut lieu à Marrakech au début de l'année $595[\ldots]^{15} »$. Ce qui peut se situer à la fin d'une année peut également se dérouler au début d'une autre. Ibn Abī Ușaybi'a fait coïncider

12. Cette opinion n'est pas partagée par E. Renan et R. Blachère.

13. « wa naqama aydan 'alà ğamā 'atin uhrā mina al-fudalā' ala'yān », « il se vengea aussi d'un autre groupe d'hommes distincts et connus » pourrait traduire l'élite intellectuelle. Cf. Ibn Abī Ușaybi'a, op. cit., p. 134-135.

14. Cf. 'Abd al-Wahīid AL-MarrāKušī, Al-muhtār min al-Mu'ğib, p. 212.

15. Cf. E. Renan, Averroès et l'averroüsme, p. 342. 
cette date avec l'avènement d'al-Nāșir. E. Renan interprète mal, semble-t-il, une phrase d'Ibn Abī Ușaybi'a qui dit : «[...] il avait plein pouvoir avec al-Manșūr ${ }^{16}$ et un haut rang dans son gouvernement et son fills al-Nāșir le respectait beaucoup également ${ }^{17}$ », ce qui fait dire à Renan : « Mais il se contredit lui-même lorsqu'il prétend qu'Ibn Rušd fut en faveur auprès de Muhammad al-Nāṣir, qui succéda à Ya qūb al-Manșūr ${ }^{18}$ le 22 de rabi ' premier de 1'an 595 (2 janvier 1199). » Pourtant, on pourrait comprendre aussi, et cela donnerait un récit plus cohérent, que son fils le respectait beaucoup même avant son accession au trône.

Le texte d'Ibn Abī Ușaybi'a coïncide avec le texte d'al-Marrākušī également dans la formule « que Dieu ait pitié de son âme » utilisée juste après avoir évoqué sa mort. Bien sūr, al-Marrākušĩ l'a beaucoup plus employée qu'Ibn Abī Ușaybi'a qui ne l'a mentionnée qu'une seule fois. Quoi qu'il en soit, bien que cette formule soit apparemment anodine et rituelle, elle exprime indirectement le sentiment de l'auteur vis-à-vis du personnage dont il retrace la biographie. Ainsi nous avons remarqué, qu'après avoir confronté plusieurs biographies du même auteur, al-Marrākušì, dans certaines, cette formule est bien présente ; par contre pour d'autres elle est absente et peut même être remplacée par une formule contraire, telle que « que Dieu le maudisse » (la 'anahu Allāh ${ }^{19}$ ).

Enfin, pour al-Dahabī, tout le début du texte semble être d'Ibn Abī Ușaybi 'a (la naissance d'Ibn Rušd, sa formation, sa connaissance de la philosophie la liste des œuvres) ce qui nous pousse à conclure que pour cette dernière source, l'auteur Ibn Abī Ușaybi 'a était déjà considéré comme une référence fiable, et légitime davantage l'intérêt de son étude.

\section{ÉLÉMENTS D’ÉTUDE ESSENTIELS DANS LA VIE D’IBN RUŠD SELON NOTRE SOURCE}

Sa formation 20

— « Il étudia sous la tutelle du juriste "faqìh" le hăfiz ${ }^{21}$ Abū Muḥammad Ibn Rizq [...] ;

— et il avait étudié les fondements de la connaissance et la médecine sous la tutelle de Abū

Ğa'far ibn Hārūn ${ }^{22}$ duquel il a puisé beaucoup de savoirs (philosophiques) [...] ;

16. Ibn Yūsuf b. 'Abd al-Mu'min, al-Manșūr, troisième souverain de la dynastie mu'minide (almohade), qui régna de 580 à 595 (1184-88) [...] Il fut proclamé à Séville le $1^{\text {er }}$ ğumādā I/10 août 1184. Il regagna rapidement Marrakech, prit le titre d'amir al-mu'minin [...] Le règne de Ya'qūb al-Manșūr marque l'apogée de l'empire almohade. Cf. A. Huici Miranda, « Abū Ya'qūb Yūsuf b. 'Abd al-Mu'min », EI², I, Leyde et Paris, 1960, p. 165-166.

17. IBN ABī UșAYBI‘A, op. cit., p. 340.

18. La dernière phrase est de E. Renan et non d'Ibn Abī Ușaybi ‘a ; de même la phrase : « [... ] et surtout lorsqu'il place le rappel d'Ibn Rušd sous al-Manșūr en cette même année 595 ».

19. Al-MarRāKuŠĩ l'emploie à l'encontre d'un certain Ibn al-Rīq et à l'encontre d'Alphonse, p. 152 et 21 du alMuhtār min al-Mu'ğib.

20. À noter que certains maîtres cités n'ont pu être identifiés.

21. Le hăfiz est la personne qui connaît non seulement tout le Coran par cœur mais aussi les six traditions principales relatives au prophète Moḥammad. Cf. Dictionnaire arabe/français, KAZIMIRSKI, t. 1, p. 460.

22. D. Urvoy nous présente ce maître ainsi : «Originaire de Trujillo, il était spécialisé en ophtalmologie. Il est signalé comme autorité tant en pharmacologie qu'en traditions prophétiques, ce qui le place avec Averroès dans le 
— et il avait étudié les notions de base et la médecine sous Abū Ğa'far Ibn Hārūn, l’a côtoyé un moment et a pris de lui beaucoup de la science philosophique $[\ldots]^{23}$. »

Ibn Abī Ușaybi'a cite en tout deux maîtres et trois matières dont la philosophie, qui peut être sous-entendue sous le terme hikma. Remarquons que les noms de maîtres qu'il a cités n'ont rien à voir avec ceux retenus par Ibn al-Abbār. Observons également la répétition du dernier maître et ce qu'il a été pour Ibn Rušd, ce qui laisse supposer que ce dernier personnage a joué un grand rôle dans la formation d'Ibn Rušd. La phrase d'Ibn Abī Ușaybi 'a est reprise à l'identique, en ce qui concerne les bases de la médecine et les sciences de la sagesse.

\section{Son réseau de relations}

a) Les maîtres

— Le faqìh, le hăfiz Abū Muḥammad ibn Rizq

— Abū Ğa'far Hārūn, maître selon un rapporteur

b) Les amis

— Abū Marwān ibn Zuhr ${ }^{24}$

— « et beaucoup de ses amis [...]»

c) Les rapporteurs

$$
\text { — Le cadi Abū Marwān al-Bāğīi }
$$

d) Les intellectuels

— «Un groupe d'étudiants [...]» pourrait correspondre aux intellectuels

— Abū Ğa'far al-Dahabī, le modèle des intellectuels et des médecins

e) Les ennemis

— « un groupe de ses ennemis $[\ldots] »$

f) Concurrent ou adversaire (direct) :

— Abū Muḥammad 'Abd al-Wāḥid ibn al-Šayh Abū Hạṣ al-Hanatānī,

\footnotetext{
même petit groupe des hommes de religion férus de savoir antique. Ibn Hārūn peut apparaître comme un bon initiateur puisque, nous dit l'historien oriental, il connaissait à la perfection les sciences philosophiques, et était versé dans les œuvres d'Aristote et des autres philosophes de l'Antiquité. » Cf. D. URvoy, Averroès, Les ambitions d'un intellectuel musulman, p. 70.

23. Cf. Iвn Aвī Ușaybi‘a, op. cit., p. 134-135.

24. C'est Abū Marwān 'Abd al-Malik Ibn Abī al-'Alā' Zuhr, désigné le plus souvent sous le nom d'Abū Marwān ibn Zuhr. Il naquit à Séville, mais sans date de naissance précise, et y mourut en 557/1161. Il suivit tout comme Ibn Rušd une formation littéraire et juridique très solide et connut également la disgrâce à Marrakech sous la dynastie almoravide en 535/1140 sans motif réellement connu, à part qu'on suppose qu'il manqua d'égard au souverain. Il y a un élément important pour nous, c'est le fait qu'il fut l'ami d'Ibn Rušd bien qu'il fût plus âgé que lui de trente années et certainement pas son maître. Nous savons aussi qu'il avait avec Ibn Rušd des liens d'étude et même une collaboration et qu'il était issu d'une famille prestigieuse, à l'instar d'Ibn Rušd, les Ibn Zuhr étant surtout connus en médecine, discipline dans laquelle ils brillèrent sur quatre générations.
} 
ami et gendre de 'Abd al-Mu'min ${ }^{25}$ et situé troisième ou quatrième dans la hiérarchie des Dix

g) Le groupe de disgraciés et d'exilés

- Abū Ğa'far al-Dahabī ${ }^{26}$

- Le faqīh Abū 'Abd Allāh Muḥammad ibn Ibrāhīm, le cadi de Bougie

- Abū al-Rabī' l'aveugle

- Abū al-'Abbās al-ḥâfiz le poète, le liseur du Coran

h) Le groupe de défenseurs

- « un groupe de gens distingués de Séville [...]».

Dans quelle tendance s’inscrit donc Ibn Abī Ușaybi ‘a ici ?

Tout cela donne l'impression qu'Ibn Rušd était bien entouré. Pas d'isolement donc du savant du monde environnant. Au contraire, on pourrait même dire qu'il y avait une interaction sociale conduisant à un mouvement dans lequel il semble être bien intégré. Le fait de relever tous ces noms qui ont joué de près ou de loin un rôle dans sa vie montre que l'auteur a pris conscience de l'influence du milieu dans lequel baignait Ibn Rušd, un milieu intellectuel bien spécifique.

\section{Sa disgrâce}

Ibn Abī Ușaybi'a parle de l'endroit où Ibn Rušd a été exilé : il dit que c'est Lucena, ville où vivait une importante communauté juive, rien de plus ${ }^{27}$. Il ne parle pas du rappel du calife, il dit seulement qu'il est mort à Marrakech.

Sur les circonstances de la disgrâce, Ibn Abī Ușaybi 'a rassemble toutes les causes qui ont pu jouer dans la décision du calife à savoir son attitude insolente envers le calife, sa fréquentation assidue du frère et concurrent direct du calife, Abū Yạ̣yā, et son grand intérêt pour une discipline mal vue à l'époque, il s'agit bien sûr de la philosophie.

Ibn Abī Ușaybi 'a ${ }^{28}$ a justifié le retour en grâce d'Ibn Rušd par le fait qu'un groupe de notables de Séville se sont interposés auprès du calife en faveur d'Ibn Rušd en témoignant de son intégrité et de sa bonne foi, ce qui fit changer la décision du calife.

25. Ibn Haldūn note à propos de 'Abd al-Mu'min, successeur du Mahdī qu'il est le véritable artisan de la fondation de l'empire almohade et le premier d'une dynastie qui régnera jusqu'en 1269. Cf. IBn Khaldūn, Peuples et nations $d u$ monde, extraits des 'Ibar, traduits de l'arabe et présentés par Abdesselam Cheddadi, 2, p. 605. À remarquer aussi que la hiérarchie des Dix a été établie à l'époque du Mahdī, et elle privilégie les premiers adhérents de la doctrine.

26. Le plus connu du groupe, Abū Ğa'far al-Dahabī a été cité par Ibn Abī Ușaybi'a. Al-Dahabī est plus jeune qu'Ibn Rušd de trente-trois ans. Il se distingue sur la scène politique de la dynastie almohade, puisqu'il a été leur porte-parole officiel. Il avait également la fonction de contrôler les juges. Après la disgrâce, al-Dahabī fut nommé « visiteur » (mizwār) des țalaba-s et des médecins. Encore une fois, le calife semble l'apprécier puisqu'il le qualifie d'or dont la qualité augmente avec la fusion. Cf. IBn ABī UșAYBi'A, op. cit., p. 134-135.

27. Ibid., p. 134-135.

28. On remarque que c'est le seul auteur arabe source qui donne les raisons de son retour en grâce. 


\section{La liste des œuvres}

$\mathrm{Au}$ vu des divergences dans la manière d'aborder et de classer les écrits d'Ibn Rušd, nous nous sommes penchés sur le seul auteur arabe source qui nous ait laissé une liste importante, non exhaustive il va sans dire, des œuvres d'Ibn Rušd. Après maintes analyses effectuées sur cette liste, il ressort que même Ibn Abī Ușaybi'a a tenté d'obéir à une classification des œuvres d'Ibn Rušd. Bien que sous-jacente, elle semble présenter un ordre logique correspondant parfaitement à ce que nous savons déjà d'Ibn Rušd.

Au demeurant, cette liste semble suivre une chronologie des œuvres d'Ibn Rušd, c'està-dire qu'elle va des tout premiers écrits d'Ibn Rušd jusqu'aux derniers en prenant en compte simultanément deux périodes distinctes dans sa vie intellectuelle : la première concerne plutôt les écrits où il est question pour Ibn Rušd de composer des livres généraux, essentiellement autour de la jurisprudence et de la médecine ; période jointe complètement au travail gigantesque des diverses catégories de commentaires philosophiques et médicaux. La seconde période donne des écrits plus personnels, dans lesquels on voit Ibn Rušd répondre, réagir, en utilisant différentes formes de compositions dont la plus importante reste la maqāla (opuscule).

Avec une telle classification, les remarques de certains auteurs sur la période de composition de chaque catégorie de commentaire restent valables. En effet, si nous suivons le classement d'Ibn Abī Ușaybi'a en y adjoignant à chaque fois les dates retenues pour certains écrits, nous sommes obligés de constater que les petits commentaires ont été rédigés entre 1157 et 1169 , les commentaires moyens entre 1170 et 1177 et qu'enfin les grands commentaires semblent plus tardifs, entre 1188 et 1190 . Ceci pour les commentaires philosophiques; pour ce qui est des commentaires médicaux, ce n'est pas du tout le cas puisqu'on note pour les commentaires moyens de Galien des années de rédaction qui fluctuent entre 1192 et 1193. C'est dire qu'Ibn Rušd ne s'est jamais désintéressé de la médecine, même vers la fin de sa vie.

Quant au domaine de la jurisprudence, il suit le même ordre : d'une part, la première période dans laquelle Ibn Rušd expose et présente la discipline et pour laquelle malheureusement on n'a pas de dates; et la deuxième période, pour laquelle nous avons des dates qui vont de 1179 pour le Kašf à 1180 pour le Fașl ou pour le Tahăfut. Inutile de préciser que cette seconde période se caractérise par des réponses, des critiques et des réactions qu'Ibn Abī Ușaybi'a a soigneusement mises à part afin de souligner probablement leur caractère personnel, tout en précisant à chaque fois qu'il s'agit de kitāb (ouvrage) alors que les autres réponses ou réflexions philosophiques ou métaphysiques d'Ibn Rušd sont toutes exprimées sous forme de maqāla (opuscule), pour lesquelles nous déplorons profondément l'absence totale de dates de rédaction. Nous supposons que tous ces opuscules appartiennent à la deuxième période de rédaction, c'est-à-dire entre 1180 et 1198.

Autre remarque importante en ce qui concerne la liste d'Ibn Abī Ușaybi‘a : sur les quatre-vingt-quatre écrits d'Ibn Rušd cités, dix-huit sont absents des fonds anciens des bibliothèques. Dans ce nombre, la majorité comprend des écrits de la deuxième période, 
principalement des opuscules de philosophie. À souligner également qu'Ibn Abī Ușaybi‘a commence sa liste d'ouvrages d'Ibn Rušd par trois titres de fiqh ; le premier kitāb al-Taḥṣīl n'est cité chez personne, le deuxième, Kitāb al-muqaddimāt, est celui du grand-père d'Ibn Rušd, et le troisième titre ressemble à s'y méprendre à Bidāyat al-muğtahid wa nihâyat almuqtașid, sauf qu'Ibn Abī Ușaybi'a inverse le titre et cite Kitāb nihāyat al-muğtahid. À l'exception de ces trois titres, tous les autres écrits cités se retrouvent dans les listes. Comme il ne s'agit pas là de la première erreur constatée dans l'ouvrage d'Ibn Abī Ușaybi'a, nous supposons que ces trois livres appartiennent au grand-père, bien que rien n'exclue la possibilité qu'Ibn Rušd lui-même ait pu les rédiger, surtout pour le premier Kitāb al-Tahṣil pour lequel

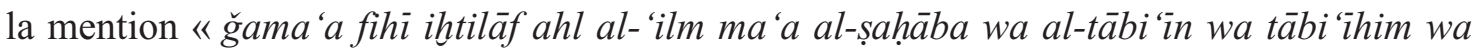
nașr mad̄āhibihim wa bayyana mawādi ' al-ihtimālāt allatì hiya mațār al-ihtilāf ${ }^{29}$ " n'est pas sans nous rappeler l'esprit du Faṣl ou Traité décisif; de même l'intérêt d'Ibn Rušd pour les questions de divergences en matière de jurisprudence que les biographes arabes ont déjà souligné.

Pour illustrer ces différentes observations, nous avons représenté à la page suivante la liste d’Ibn Abī Ușaybi‘a sous forme de graphique qui reflète l'ordre suivi par ce dernier et montre clairement le parcours intellectuel d'Ibn Rušd.

À travers ce schéma synthétique qui reprend exactement l'ordre dans lequel Ibn Abī Ușaybi'a a cité les œuvres d'Ibn Rušd, on distingue naturellement les deux grandes périodes, représentées chez cet auteur par des termes spécifiques tels que : kitāb, ğawāmi ', talhīṣ, šarh , suivis toujours du nom de l'auteur qu'Ibn Rušd a commenté, en l'occurrence Aristote en majorité pour les questions de logique et Galien pour les questions médicales. Ceci pour la première période.

En revanche, des termes comme yaruddu (a répondu) pour présenter le Tahäfut d'Ibn Rušd ou de radd (réponse) pour l'opuscule sur Ibn Sīnā ou même de fash ${ }^{30}$ pour signaler un autre opuscule de ceux qui contredisent Aristote, indiquent clairement l'objectif de leur auteur, ainsi que le côté plus personnel et nettement actif d'Ibn Rušd vis-à-vis des détracteurs de sa philosophie, sans négliger le fait que tous ces opuscules et questions diverses ont été réalisés dans un esprit d'éclaircissement et de transmission d'un aristotélisme pur.

À l'examen de ce schéma, nous pouvons donc déduire un certain nombre d'observations concernant les travaux d'Ibn Rušd. Un critère de cohérence semble les réunir malgré la diversité des formes d'écrits, du plus petit au plus volumineux. On peut dire sans conteste qu'Ibn Rušd a exploité toutes les formes de rédaction en ne sacrifiant aucune d'elle au profit d'une autre. Tout semble donc revêtir un certain équilibre, que ce soit au niveau de la forme ou au niveau du domaine traité. Si c'est le juridique, Ibn Rušd suit une même évolution que pour les autres disciplines. D'abord une présentation générale de ladite discipline dans la première période de sa vie ; ensuite, des réponses et des réactions pour aboutir à une méthode qu'il va préconiser dans la seconde période.

29. Cf. Iвn Abī Ușaybi`A, op. cit., p. 532.

30. Ne possédant pas un moyen de vérification, nous supposons que ce terme fash, qui équivaut à réfuter, est employé par Ibn Abī Ușaybi‘a. 
PREMIÈRE PÉRIODE

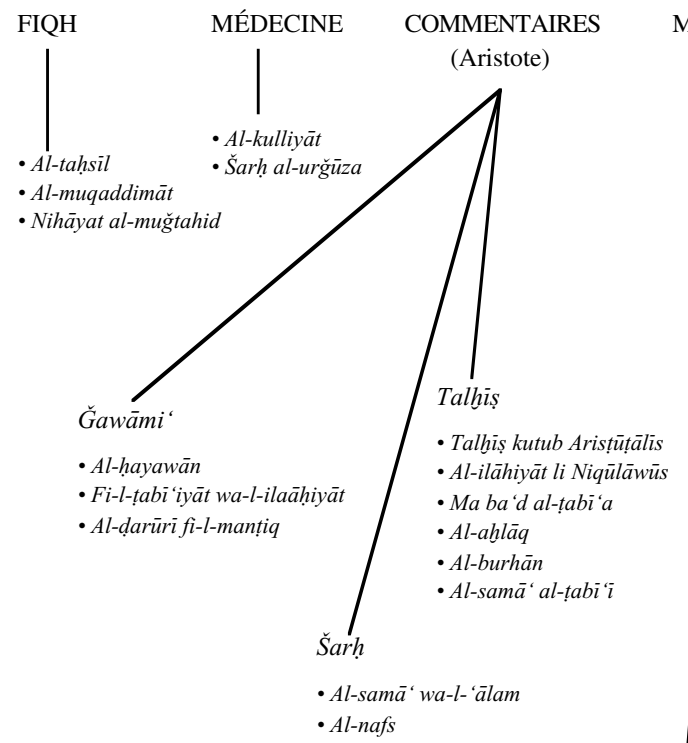

Talhiș

- Al-ustuqussāt

- Al-mizāăg

- Al-qiwā al-țabi 'ìya

- Al-ilal wa-l-a rad

- Al-ta'arruf

- Al-hummayāt

- Awal kitāb al-adwiya almufrada

- Al-nisf al-tānin min kitāo hillat al-bur'

Galien)

\section{DEUXIÈME PÉRIODE}

RÉPONSES COMPOSITIONS MÉDECINE

1

- Tahāfut al-tahāfut

- Minhāğ al-adilla

- Fașl al-maqāl fi ma

bayna al-hikma wa-l-

šarì 'a min al-ittișāl

Maqāla
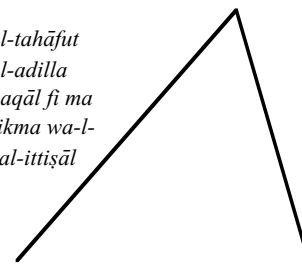

- Fi-l-'aql

- Fi-l-qiyās

- Fi fahs hal yumkin al- 'aql alladì

finā wa huwa al-musammā bi-l-

hayūlāni an ya 'qil al-șuwar al-

mufäriqa bi ahirihi aw la yumkin

dālik wa huwa al-mațlūb allad̄i kāna

Arisțùțālis wa 'adanā bi-l-fahṣ 'anhu

fi kitāb al-nafs

- Fì anna mā ya taqiduhu al-

maššà' ūn wa mā ya 'taqidudu al-

mutakallimūn min ahl millātinā $f i$

kayfiyyat wuğūd al- 'ālam mutaqārib

fi al-ma'nā

- Fi-l-ta 'ríf bi ğihāt naẓar Abì Nașr fi

kutubihi al-mawd̄̄ 'a fi sinā'at al-

manțiq allatì bi aydì al-nās wa bi ğihat

naz̧ar Aristutuāalis fihā wa miqdār mā fi

kitābùin ağzā' al-șinā 'a al-mawğūda $f i$

kutub Aristūṭālīs wa miqdār mā zād

ihtilāf al-nazar ya 'nī nazarihimà

- Fì ittișāl al- 'aql al-mufāriq bi-l-

insān

- Fì ittișāl al 'aql bi-l-insān

- Al-masā'ìl

al-muhimma 'ala kitāb

al-burhān

- Šarh kitāb al-qìyās

- Kitāb fi fahș masa'il waqa 'at fi al-

'ilm al-ilāhi fi kitāb al-Šifā' li Ibn

Sinä

- Masa îl fi-l-zamān

- Fi fash šubuhāt man i tarada'alā

al-hikm wa burhānihi fi wuğūa al-

mādda al-ūlā wa tabyīn anna burhān

Arisțutālis huwa al-ḥaqq al-mubin

- Al-rad 'ala Abì 'Alì Ibn Sinā fi

taqsimihi al-mawğūāàt ilā mumkin

'alā al-iṭlāq wa mumkin bi d̂âtihi

wāğib bi gayrihi

- Masā'il fi-l-hikma

- Fi harakat al-falak

- Kitāb fima halaf Abū Nașr li

Aristūtālis fi Kitāb al-burhān min

tartibihi wa qawānin al-barāhīn wa-

l-hudūd.

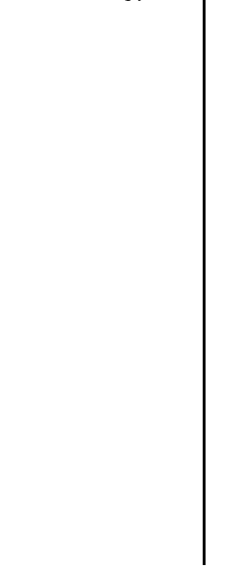

- Murāğa 'āt wa mabāhịt bayna Abi Bakr Ibn

Tufayl wa bayn Ibn Rušd fi rasmihi li-l-dawā' fi kitābihi al-mawsūm bi-lkulliyāt

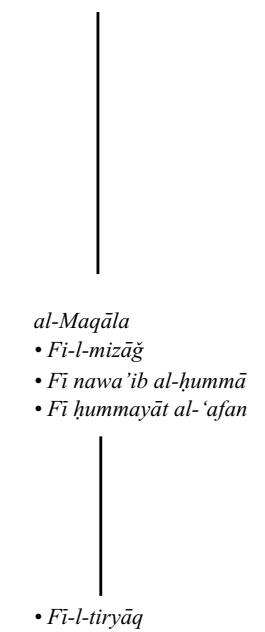


Un coup d'œil également sur les différents commentaires réalisés par lui montre bien ce côté d'abord d'initiateur à une science, à un savoir, durant la première période ; puis vient le cycle des maqāla dans lesquels Ibn Rušd s'érige en maître de ce savoir, et nous voyons les noms des précurseurs de ce savoir disparaître totalement des titres. Cette deuxième période se caractérise aussi par des révisions, des refontes ou des corrections : murāğa 'āt, fahṣ, šarh, masā'il. On ne s'étonnera donc pas de voir apparaître, dans cette période précisément, encore des grands commentaires, tel celui du syllogisme d'Aristote, ou des questions, telles que de la démonstration d'Aristote.

Bien sûr, un lecteur avisé notera une fluctuation toute minime vers la fin de la liste d'Ibn Abī Ușaybi'a. On dirait que certains écrits d'Ibn Rušd ont échappé à sa classification ; ne sachant où les placer, Ibn Abī Ușaybi'a les a relégués en fin de liste. Cette fluctuation se fait sentir au moment où il cite les Masā'il fi al-ḥikma puis l'opuscule d'astronomie, l'ouvrage sur les divergences entre al-Fārābī et Aristote, et finalement l'opuscule sur le thériaque ou des médicaments. La seule explication que nous pouvons donner à cela est le penchant disciplinaire de l'auteur luimême et non pas d'Ibn Rušd. Pour s'en rendre compte, il suffit de noter qu'Ibn Abī Ușaybi'a a débuté sa liste par des ouvrages juridiques, ouvrages d'ailleurs dont l'authenticité fait défaut. De même, dans la deuxième période, il commence par les ouvrages juridiques.

Il est à signaler tout de même une certaine impartialité de l'auteur, puisque, malgré l'intérêt d'Ibn Abī Ușaybi'a pour le domaine médical, les travaux d'Ibn Rušd dans ce domaine viennent en fin de liste que ce soit pour la première période ou pour la deuxième période, car ne l'oublions pas Ibn Abì Ușaybi a n'a pas manqué de signaler dans la biographie d'Ibn Rušd le penchant de ce dernier pour le domaine philosophique. Finalement, et de manière générale, l'auteur a respecté non seulement la chronologie des œuvres d'Ibn Rušd mais aussi les disciplines dans lesquelles elles sont apparues et les diverses formes empruntées par Ibn Rušd.

\section{Ce que reflète l'œuvre globale d'Ibn Rušd}

Trois principes se dégagent donc de l'œuvre d'Ibn Rušd : harmonisation des écrits, richesse des formes et maturité des idées. Restent cependant quelques questions qui demandent une recherche historique plus poussée ; à savoir, pour quelle raison à l'époque d'Ibn Abī Ușaybi 'a certains manuscrits d'Ibn Rušd sont présents ou, en tout cas, la liste de ces manuscrits, alors que dans les listes des bibliothèques des fonds anciens datant du Moyen-Âge, ces mêmes manuscrits sont absents?

Ensuite, il y a la question de certains écrits fondamentaux attribués à Ibn Rušd qui ne sont pas du tout cités par Ibn Abī Ușaybi 'a, tel que Ğawāmi ‘ siyāsat Aflațūn. L'hypothèse la plus probable provient des objectifs de l'auteur. Nous en avons précédemment signalé les points essentiels relevés à propos du « groupe d'hommes sages et de philosophes s'occupant de la science médicale » pour lesquels Ibn Abī Ușaybi 'a a proposé de citer « des sommes de leurs conditions et anecdotes ainsi que les titres de leurs livres ». Ce qui suppose, comme 
nous l'avons signalé en note, que cette catégorie de médecins philosophes sera traitée sommairement, de même pour la liste de leurs ouvrages. Tout ceci est facilement vérifiable si on effectue une comparaison avec l'autre catégorie, celle des médecins à part entière. Ibn Abī Ușaybi'a leur a consacré beaucoup plus de pages et a cité intégralement, quand il le pouvait, la liste de leurs œuvres.

Si cette constatation permet de répondre à un grand nombre de questions que nous nous posons à propos de l'élaboration par Ibn Abī Ușaybi ‘a de la liste des œuvres d'Ibn Rušd, ce qui a motivé son choix pour tel titre par rapport à tel autre semble très difficile à déterminer, vu que nous avons relevé quelques ouvrages juridiques mentionnés par la liste de l'Escurial et même par Ibn al-Abbār tels que Muhtaṣar al-mustaşfā mais non mentionnés par Ibn Abì Ușaybi 'a. Grande surprise aussi quand on lit sur la liste de l'Escurial un titre d'un ouvrage médical Talhịs al-A 'ḍ̄a' al-ālima, ou même d'un opuscule titré Maqāla fi hifzz al-șiḥha en plus de trois autres opuscules concernant le domaine médical, tant et si bien que nous commençons à présent à douter qu'Ibn Abī Ușaybi'a ait opéré un réel choix sur une liste exhaustive en sa possession.

Par contre, il est plausible que les différents talhịs de logique trouvés sur d'autres listes et non chez lui aient été omis sciemment, puisqu'il nous signale, avant de citer les commentaires moyens d'Aristote, qu'Ibn Rušd avait effectué un travail complet et global sur tous ces commentaires « [...] mulhaq bihi talhịs kutub Arisțūțāìs, wa qad lahhaṣahā talhịșan tāmman mustawfiyan $[\ldots]^{31} »$.

Cette constatation est d'une importance capitale car elle touche la question de la préservation des œuvres d'Ibn Rušd en particulier, et des œuvres des intellectuels andalous de différentes époques en général. En raison de la mauvaise réputation de la philosophie en terre d'islam, et notamment en Andalousie, des différentes crises politiques, de l'instabilité des pouvoirs en place, de la disparition de la dernière trace de civilisation arabo-musulmane en Espagne à Grenade, de la reconquête lente et progressive des chrétiens, et de tout ce qui en résulte en temps de guerre comme perte, ce qui a été sauvé et sauvegardé jusqu'à nos jours est dû certainement à un énorme effort ; d'abord d'assimilation de cette sagesse, ensuite de traduction et d'interprétation hébraïques et latines. Ce qui subsiste de nos jours, ce sont quelques vestiges poussiéreux de ce lointain passé, vestiges d'un esprit de travail et de pensée.

En conclusion, les remarques émises par J. Langhade et D. Mallet à propos d'Ibn Abī Ușaybi'a nous semblent d'une réelle importance et elles justifient bien notre choix de cet auteur source pour discuter de l'inventaire des œuvres d'Ibn Rušd : « La notice d'Ibn Abī Ușaybi'a sur Averroès est l'une des plus riches que nous ayons et présente une longue liste des titres de son œuvre. Il fait une grande place à sa production philosophique ${ }^{32}$. »

31. Cf. Iвn Abī Ușaybi'A, 'op. cit., p. 532.

32. Cf. J. Langhade et D. Mallet, « Droit et Philosophie au XII ${ }^{\mathrm{e}}$ siècle dans al-Andalus. Averroès (Ibn Rušd) », ROMM 40, 1985 - 2, p. 103. 
Bien entendu, le fait que cette source nous semble plus sûre vient du fait que l'autre liste de l'Escurial citée par E. Renan, bien que plus complète, pose un réel problème en tant que document historique certifié du fait que son auteur est anonyme. Par conséquent, l'époque et le lieu où elle a été élaborée étant inconnus, la validité de cette liste demeure suspecte, d'autant plus que nombre des manuscrits cités n'ont pas de version arabe et ne se trouvent qu'en version hébraïque ou latine, parfois même sans aucune traduction.

\section{TABLEAU RÉCAPITULATIF DES ÉLÉMENTS MENTIONNÉS DANS LE TEXTE D’IBN ABĪ UȘAYBI‘A}

\begin{tabular}{|c|c|c|c|c|c|c|}
\hline $\begin{array}{c}\text { Le titre } \\
\text { donné à Ibn } \\
\text { Rušd }\end{array}$ & La famille & La formation & Les œuvres & $\begin{array}{c}\text { Relation avec } \\
\text { le pouvoir }\end{array}$ & La disgrâce & $\begin{array}{c}\text { Les apports } \\
\text { d'Ibn Rušd }\end{array}$ \\
\hline $\begin{array}{c}\text { Le cadi Abū } \\
\text { al-Walīd 33 }\end{array}$ & $\begin{array}{c}\text { aucun } \\
\text { élément } \\
\text { particulier }\end{array}$ & $\begin{array}{c}\text { Maîtres et } \\
\text { domaines }\end{array}$ & $\begin{array}{c}\text { Longue liste } \\
\text { de toutes les } \\
\text { disciplines y } \\
\text { compris la } \\
\text { philosophie }\end{array}$ & $\begin{array}{c}\text { Place } \\
\text { importante } \\
3^{\text {ème }} \text { ou 4ème } \\
\text { rang dans } \\
\text { la classe des } \\
\text { Dix des } \\
\text { Almohades }\end{array}$ & $\begin{array}{c}\text { Les mêmes } \\
\text { motifs qu'al- } \\
\text { Marrākušī } \\
\text { en plus des } \\
\text { noms des } \\
\text { autres exilés }\end{array}$ & $\begin{array}{c}\text { Talents } \\
\text { juridiques et } \\
\text { dans les } \\
\text { controverses }\end{array}$ \\
\hline
\end{tabular}

\section{IMAGE D’IBN RUŠD CHEZ IBN ABĪ UȘAYBI‘A :}

Il semblerait qu'Ibn Abī Ușaybi'a n’arrive pas vraiment à situer Ibn Rušd puisqu’au tout début, il le décrit par ces termes : «prenant soin d'acquérir les sciences, incomparable dans la connaissance de la jurisprudence musulmane (fiqh) et la dialectique (hiläf), [donc Ibn Abī Ușaybi'a est bien conscient du fait qu'Ibn Rušd a un savoir plutôt encyclopédique puisqu'il précise] et il était également distingué dans la science médicale », (« [...] mu 'tani bitahṣill al'ulüm awhad fì 'ilm al-fiqh wa al-hiläf ${ }^{34}$ '”.

Pour ce qui est de la philosophie, le terme n'est même pas mentionné chez Ibn Abī Ușaybi 'a et la seule fois où il parle de « sagesse et sciences des anciens », (« [...] muštagìilūna bil-hikmati wa 'ulümi al-awā' $i l^{35}{ }^{35}$ c'est pour exposer les raisons de sa disgrâce, « [...] wa annahu fa 'ala bihim d̂ălik bi-sababi mā yudda 'à fihim annahum muštagilūna bil-ḥikmati wa 'ulūmi al-awā'il [...] ${ }^{36}$ ». Donc, le côté philosophique d'Ibn Rušd n'a pas du tout fait l'objet d'une attention particulière chez Ibn Abì Ușaybi'a pourtant il ne pouvait l'ignorer vu l'énumération considérable de ses œuvres dont la grande partie se trouve être des commentaires philosophiques. Le fait que cet auteur s'intéresse beaucoup à la médecine peut-il justifier cette attitude ? À priori, il semblerait que pour Ibn Abī Ușaybi'a, cette discipline ne revêt pas le prestige que lui prête le premier auteur arabe source d'Ibn Rušd, al-Marrākušì.

33. Il le nomme deux fois, au tout début et vers la fin du texte quand il parle de sa mort.

34. Cf. Iвn Abī Ușaybi ‘a, op. cit., p. 134-135.

35. Ibid.

36. Ibid. 


\section{CONCLUSION}

Après avoir passé en revue brièvement les cinq principaux biographes d'Ibn Rušd, notre choix s'est arrêté sur un biographe qui se situe au milieu de cette liste. Un milieu représenté non seulement par la date historique, mais également par le statut du biographe lui-même, qui se trouve être le seul homme de science dans la liste.

Nous ne manquerons pas de signaler que c'est aussi un regard venu de l'Orient qui se pose sur l'Occident musulman avec ses savants célèbres. Le regard d'Ibn Abī Ușaybi'a est plus global, plus équilibré dans sa représentation de la vie et la carrière d'Ibn Rušd. En effet, il ne privilégie aucun côté d'Ibn Rušd en délaissant les autres. Al-Marrākušĩ avait mis en relief plutôt le côté philosophique, Ibn al-Abbār plutôt le côté théologique, et pour al-Ansārī, c'est l'affaire juridique « Ibn Rušd » qui l'emporte dans son récit sur Ibn Rušd ; quant à alDahabī, il compile tous les renseignements en sa possession issus des biographes précédents.

La démarche d'Ibn Abī Ușaybi'a demeure honnête dans son ensemble puisqu'il avoue le grand intérêt d'Ibn Rušd pour la philosophie, même si on sent que ça le dérange quelque peu, étant donné qu'il n'emploie jamais le terme philosophie et attribue les raisons de la disgrâce d'Ibn Rušd à son penchant pour cette discipline. En réalité, sa biographie d'Ibn Rušd rassemble les éléments essentiels de sa vie, à savoir, sa formation, sa carrière, son lien avec le pouvoir, ses écrits, sa disgrâce.

Nous avons également vu que les commentaires des auteurs contemporains sur les sources arabes, notamment sur celle d'Ibn Abī Ușaybi'a, corroborent le fait que nous pouvons nous appuyer en toute quiétude sur cet auteur pour relever des informations utiles sur le parcours intellectuel d'Ibn Rušd depuis sa jeunesse jusqu'à sa mort. Des auteurs comme L. Gauthier, S. Munk et E. Renan confirment que ses données historiques sont dignes de foi. Par conséquent, utiliser des éléments fournis par un auteur qui a rédigé ses Tabaqāt quarante ans après la disparition d'Ibn Rušd est tout à fait opportun pour saisir les différents aspects de la vie et de la personnalité d'Ibn Rušd ainsi que la valeur de son œuvre en tant que juriste, médecin et philosophe. Nous estimons que malheureusement ces sources historiques sont très sommairement étudiées et analysées ; pourtant elles peuvent constituer une source claire pour aborder toute étude sur Ibn Rušd. 
BIBLIOGRAPHIE

AL-ANȘĀRĪ, Abū 'Abd Allāh (ibn ‘Abd al-Malik al-Marrākušī Muḥammad ibn Muḥammad),

1065-1984 al-Dayl wa al-takmila li kitāb al-mawșūl wa al-șila

Tome I, édité par Iḥsān 'Abbās, Beyrouth

Tomes IV et V édités par Iḥsān 'Abbās, Beyrouth

Tome VI édité par Iṇsān 'Abbās, Beyrouth

Tome VIII, édité par Bencherifa, Rabat, 1984.

AL-DAHABĪ

1979 Kitāb duwal al-Islām, trad. annotée des années 447/1055-6 à 656/1258, lexique et index par Arlette Nègre, Damas, IFEAD.

AVERROÈS

1996 Le Livre du Discours décisif, traduction inédite de Marc Geoffroy et introduction d'Alain de Libera, Paris, collection Bilingue, GF - Flammarion.

BADAWĪ, 'Abd al-Raḥmān

1984 Mawsū'at al-falsafa, [Encyclopédie de philosophie], première partie, Beyrouth,

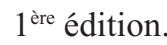

1987 La Transmission de la philosophie grecque au monde arabe, cours professé à la Sorbonne en 1967, $2^{2 m e}$ édition revue et augmentée, Paris, Librairie philosophique J. Vrin.

1998 Averroès (Ibn Rušd), Librairie philosophique J. Vrin, Paris.

FAḦR̄, M.

1960 Ibn Rušd faylasūf Qurțba, Beyrouth, al-Maṭba'at al-kațūilikiyya.

IBN ABĪ UȘAYBI‘A, Muwaffaq al-Dīn

'Uyūn al-anbā' fi țabaqāt al-ațibbā', revue par Nizār Riḍā, Beyrouth, 1965.

IBN AL-ABBĀR, Abū 'Abd Allāh Muḥammad

Kitāb al-takmila li Kitāb al-șila

1887 Édition Codera, Madrid, 2 vol.

1915 Appendice a la edicion Codera par M. Alarcon, Madrid.

1920 Édition Bel et Bencheneb, Alger.

1956 Édition par Izzat al-Attar, Le Caire, 2 vol.

LANGHADE, J. et MALLET, D.

1985 « Droit et philosophie au XII ${ }^{e}$ siècle dans al-Andalus. Averroès (Ibn Rušd) », extrait de la ROMM, 40.

AL-MARRĀKUŠİ, 'Abd al-Wahịid

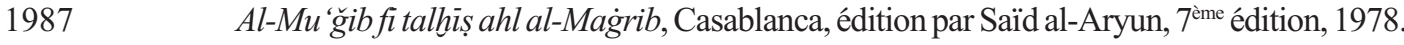


RENAN, E.

1949

CEuvres complètes, Averroès et l'averroïsme, tome III, 1852, édition définitive établie par Henriette Psichari, Calmann-Lévy.

1997

Averroès et l'averroïsme, préface d'Alain de Libera, Maisonneuve et Larose.

\section{AL-ZEREKLY,}

1989

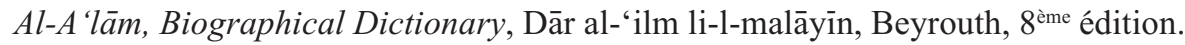

